\title{
Studies on Microbial Quality, Protein Yield, and Antioxidant Properties of Some Frozen Edible Insects
}

\author{
Peter Kurdi (D), Patspon Chaowiwat, Jirathit Weston, and Chanida Hansawasdi \\ Food Science and Technology, Science Division, International College, Mahidol University, Buddhamonthon 4 Rd, Nakhonpathom, \\ Salaya 73170, Thailand \\ Correspondence should be addressed to Peter Kurdi; peter.kur@mahidol.edu
}

Received 31 January 2021; Revised 1 March 2021; Accepted 10 March 2021; Published 24 March 2021

Academic Editor: Chaowalit Monton

Copyright (C) 2021 Peter Kurdi et al. This is an open access article distributed under the Creative Commons Attribution License, which permits unrestricted use, distribution, and reproduction in any medium, provided the original work is properly cited.

\begin{abstract}
This research investigated the microbial quality and the protein contents of Thai commercial frozen products of silkworm (Bombyx mori), bamboo caterpillar (Omphisa fuscidentalis), and field cricket (Gryllus bimaculatus). Total mesophilic aerobic counts were about 8-8.4 log cfu/g, while lactic acid bacteria numbers were up to $5.2 \mathrm{log} \mathrm{cfu} / \mathrm{g}$ samples. Yeasts and mold as well as Enterobacteriaceae numbers were found to be no more than 6.3 and $6.6 \mathrm{log} \mathrm{cfu} / \mathrm{g}$, respectively, while Clostridium spp. enumeration detected 3.2-3.6 cfu per gram frozen insect samples. The protein content in cases of cricket and bamboo caterpillar after the Soxhlet defatting method and the Folch lipid extraction combined with isoelectric point precipitation were similar when compared at $\mathrm{pH} 3.5$ or $\mathrm{pH} 4.5$. In contrast, the protein yield from silkworm was higher at $\mathrm{pH} 3.5$ in the Soxhlet defatted sample, as opposed to the Folch method treated sample where higher protein yield was obtained at $\mathrm{pH}$ 4.5. Furthermore, 2,2diphenyl-1-picryl-hydrazyl (DPPH) radical scavenging activity and ferric reducing antioxidant power (FRAP) of field cricket subcritical water $\left(121\right.$ or $135^{\circ} \mathrm{C}$ for 15 or 30 minutes) hydrolysates were also measured on a pilot basis. These tests revealed higher antioxidant activities in treated samples than in the untreated control. The highest DPPH radical scavenging activity and FRAP values were detected in samples treated at $135^{\circ} \mathrm{C}$, while the protein content of these samples was lower than that of the untreated control. These results indicate that hydrolytic compounds of proteins and probably other types of cricket materials are possibly involved in the antioxidant activities of the treated defatted cricket samples.
\end{abstract}

\section{Introduction}

It is widely accepted that the human population on planet Earth would reach 9 billion by 2050, and one of the huge challenges of the $21^{\text {st }}$ century is to produce enough food for everyone. For this reason, global interest towards alternative and novel food sources has been increased including the recent "rediscovery" of edible insects, especially in western societies. Growing insects has several economic and ecological advantages over traditional farm animals, such as less water, land, and feed requirements for their life cycles, high feed conversion efficiency, and rapid reproduction, as well as less greenhouse gas emission during the rearing process [1]. In many countries of Africa and Asia insects are traditional ingredients of the local cuisine being a good source of high-quality proteins, essential amino acids, and insoluble dietary fiber (chitin) as well as polyunsaturated fatty acids, minerals (e.g., Fe, Zn, and $\mathrm{K}$ ), and vitamin B1 and B2 [1].

In Thailand, several kinds of edible insects are consumed as deep-fried snacks including bamboo caterpillar (Omphisa fuscidentalis), silkworm (Bombyx mori), and field cricket (Gryllus bimaculatus), which are also available at supermarkets in uncooked, frozen packages. Although these frozen products are generally perceived by Thai customers as safe, studies assessing the microbial load of these are lacking. This study is aimed to investigate the microbial quality of commercially available frozen bamboo caterpillar (Omphisa fuscidentalis), silkworm (Bombyx mori), and field cricket (Gryllus bimaculatus) products. Besides, protein extraction procedures after two different kinds of lipid removal methods were also investigated, potentially aiding technological processes aiming to extract and purify insect proteins from the above 
species as the most important nutritional component of edible insects.

Recently, subcritical water extraction is gaining increased attention as it utilizes water molecules as solvent and catalyst above both boiling temperature and atmospheric pressure. It is also a cost-effective and environmentally safe method that offers great potential to extract valuable, especially nonpolar compounds from biological samples. Additionally, novel nutritional benefits of edible insect were revealed by a recent work that reported antioxidant properties in both the liposoluble and water-extracts of insects [2]. Similarly, defatted flours and hydrolysates of several edible insects were also found to possess antioxidant activities by Botella-Martinez et al. [3] and Zielińska et al. [4], respectively. Therefore, as a novel approach, subcritical water extraction was applied on defatted field crickets to gain more insights about the antioxidant properties such as DPPH free radical scavenging activities and ferric reducing antioxidant power of these edible insects.

\section{Materials and Methods}

2.1. Materials. Frozen insects: silkworm (Bombyx mori), bamboo caterpillar (Omphisa fuscidentalis), and field cricket (Gryllus bimaculatus) were purchased from a local supermarket in Bangkok, Thailand. The purchased insect samples were stored at $-4^{\circ} \mathrm{C}$. Folin and Ciocalteu's phenol reagent, 2,2diphenyl-1-picrylhydrazyl (DPPH), 2,4,6-Tris(2-pyridyl)-striazine (TPTZ), and bovine serum albumin (BSA) were purchased from Sigma-Aldrich (St. Louis, MO, USA). Iron (II) sulfate heptahydrate was purchased from Merck Millipore (Darmstadt, Germany). All the reagents used were of analytical grade.

2.2. Microbiological Analysis. Microbial analysis of frozen insect samples was based on the work of Fasolato et al. [5] and focused on total microbial count, lactic acid bacteria, yeasts and molds, Enterobacteriaceae, and Clostridium perfringens. Five grams of sample was weighed and mixed with $5 \mathrm{~mL} 0.9 \%$ saline solution. The mixture was then homogenized using a homogenizer (IKA T10 basic, IKA-Werke $\mathrm{GmbH} \&$ Co., Staufen, Germany) equipped with sterilized blades for 15 minutes or until fully homogenized.

Aerobic mesophilic microorganisms were enumerated on plate count agar (PCA, HiMedia Laboratories, Mumbai, India) incubated at $30^{\circ} \mathrm{C}$ for 48 hours. Enterobacteriaceae were counted on violet red bile glucose agar (VRBG, HiMedia Laboratories), after incubation at $37^{\circ} \mathrm{C}$ for 24 hours. Lactic acid bacteria were enumerated on de Man, Rogosa, and Sharpe agar (MRS, Laboratorios Conda S.A., Madrid, Spain), incubated at $30^{\circ} \mathrm{C}$ for 48 hours. Yeasts and molds were counted on oxytetracycline glucose yeast extract (OGY) agar after incubation at $25^{\circ} \mathrm{C}$ for 5 days. OGY agar was prepared by mixing $\mathrm{D}$-glucose $(20 \mathrm{~g} / \mathrm{L})$, yeast extract $(5 \mathrm{~g} / \mathrm{L})$, and bacteriological agar $(15 \mathrm{~g} / \mathrm{L})$ with distilled water. The solution was autoclaved at $121^{\circ} \mathrm{C}$ for 15 minutes. Oxytetra Selective Supplement (HiMedia Laboratories) was then aseptically added to the autoclaved and cooled medium $\left(45-50^{\circ} \mathrm{C}\right)$ before pouring plates. Clostridium perfringens was enumerated on tryptose sulphite neomycin agar (TSN, HiMedia Laboratories) at $46^{\circ} \mathrm{C}$ for 24 hours in anaerobic atmosphere (generated with Anaero Pack, Mitsubishi Gas Chemical Co., Tokyo, Japan). All determinations were conducted in triplicates.

2.3. Analysis of Crude Protein Content. Total protein content was determined by the Kjeldahl method. The method was performed according to method 981.10 of the AOAC [6]. All the insect samples were analyzed twice using a steam distillation system (Vapodest 20, C. Gerhardt GmbH \& Co. KG, Königswinter, Germany). The amount of obtained total nitrogen of the insect samples was multiplied by speciesspecific conversion factor of 4.76 as recommended by Janssen et al. [7] in order to not overestimate the total protein content.

\subsection{Lipid Extraction}

2.4.1. Soxhlet Extraction. Hot air-dried samples ( $5 \mathrm{~g}$ ) were ground by blender before defatting using a Soxhlet apparatus (Biosolve, Dieuze, France) with $400 \mathrm{~mL}$ petroleum ether as a solvent following the official AOAC method (991.36; [6]). The extraction cycle ran for 3 hours for silkworm and for 2 hours 30 minutes for bamboo caterpillar and field cricket. The extracts were dried for 24 hours at room temperature to remove residual solvent. The defatted residues were kept in a desiccator before use.

2.4.2. Folch Extraction. This lipid extraction method was adopted from Tzompa-Sosa et al. [8] based on the principle of phase separation between polar and nonpolar solvents. Ten grams of ground dried samples was prepared in each centrifuge bottle; then, $200 \mathrm{~mL}$ dichloromethane and methanol were added at a ratio of $2: 1$. The mixtures were shaken for 20 seconds, then sonicated in a benchtop sonicator washer for 10 minutes, and placed in a laboratory shaker water bath for 2 hours at $150 \mathrm{rpm}$ in room temperature. Afterwards, $25 \mathrm{~mL}$ distilled water was added into the mixtures and centrifuged for 20 minutes at $10,000 \times \mathrm{g}$ in room temperature. After the centrifugation, there were 3 layers separated. The top layer, composed of nonlipid and polar components, was pipetted out by glass pipette. The middle layer, composed of lipid components dissolved in the solvent, was discarded. The bottom part composed of insoluble residues was also collected. The collected parts were cooled and dried for 24 hours at room temperature to remove residual solvent then later used as defatted protein in further protein isolations.

2.5. Protein Isolation Using Isoelectric Point Precipitation. The protein extraction method was a modified version of what was described by Gresiana et al. [9]. Eight grams of defatted insect powder was suspended in $80 \mathrm{~mL}$ of distilled water and stirred for 1 hour. The mixture was subjected to vacuum filtration, and the supernatant was later used in the protein isolation process. The $\mathrm{pH}$ of the crude protein extract was adjusted to 3.5 or 4.5 then stirred for 10 minutes followed by centrifugation for 10 minutes $\left(10,000 \times g, 4^{\circ} \mathrm{C}\right)$. (These $\mathrm{pHs}$ were proven to yield the most protein amounts among the $\mathrm{pHs}$ tested in a preliminary experiment.) The pellets were 
collected and dried by hot air at $55-60^{\circ} \mathrm{C}$ for 1 hour. The dried protein isolate was weighed to calculate the yield percentage of isolation. The isolated protein was then grounded and dissolved in $2 \mathrm{M} \mathrm{NaOH}$ and distilled water in the ratio of $1: 9$, resulting in a total concentration of $1 \mathrm{mg} / \mathrm{mL}$ which was later used in Lowry protein assay (see below).

2.6. Protein Content Determination. The total protein content was measured by the Lowry method according to Waterborg [10]. The protein reagent was prepared by mixing $2 \%$ $\mathrm{CuSO}_{4} \cdot 5 \mathrm{H}_{2} \mathrm{O}, 3 \% \mathrm{KNaC}_{4} \mathrm{H}_{4} \mathrm{O}_{6} \cdot 4 \mathrm{H}_{2} \mathrm{O}$, and $3 \% \mathrm{Na}_{2} \mathrm{CO}_{3}$ in $0.1 \mathrm{M} \mathrm{NaOH}(1: 1)$. This solution was mixed in a $1: 1: 98$ ratio prepared freshly before use. The insect protein isolate samples $(0.2 \mathrm{~mL})$ were mixed well with $2.0 \mathrm{~mL}$ of protein reagent and incubated at room temperature for 10 minutes. Afterwards, $0.2 \mathrm{~mL}$ of $50 \%$ Folin and Ciocalteu's phenol reagent was added into the mixture and incubated at room temperature for another 30 minutes. The absorbance of the samples was measured in a spectrophotometer (Spectronic 200, Thermo Scientific, Waltham, MA, USA) at $660 \mathrm{~nm}$, and the protein concentration was determined using a standard curve made by measuring absorbances of bovine serum albumin solutions between 0 and $1 \mathrm{mg} / \mathrm{mL}$ concentrations. The results were analyzed by T-test at $95 \%$ confidence and presented as mean \pm standard deviation $(\mathrm{SD})$.

2.7. Hydrothermal Treatment of Defatted Crickets. Frozen whole field crickets $(2 \mathrm{~g})$ were defatted by the Soxhlet method as described above except that the extraction cycle was run for 1 hour. Defatted crickets were mixed in flasks with water by the ratio of $1: 1$. The flasks were then autoclaved in the following conditions: $121^{\circ} \mathrm{C}$ for 15 minutes, $121^{\circ} \mathrm{C}$ for 30 minutes, $135^{\circ} \mathrm{C}$ for 15 minutes, and $135^{\circ} \mathrm{C}$ for 30 minutes. All samples were cooled down and vacuum filtered to obtain supernatant of cricket hydrolysates and were subsequently freeze-dried. The protein content of the freeze-dried cricket hydrolysates was measured by the Lowry method as described above.

2.8. 2,2-Diphenyl-1-Picryl-Hydrazyl (DPPH) Radical Scavenging Assay. The DPPH free radical-scavenging activities of cricket hydrolysates were determined according to Bougatef et al. [11]. Freeze-dried cricket hydrolysate was dissolved in deionized water to have $1 \mathrm{mg} / \mathrm{mL}$ protein content, and this mixture was served as sample in the assay. $125 \mu \mathrm{L}$ of $0.02 \% \mathrm{DPPH}$ in $99.5 \%$ ethanol was mixed with $1 \mathrm{~mL}$ of samples then subsequently incubated in the dark at room temperature for 60 minutes. Afterwards, the absorbance of the samples at $517 \mathrm{~nm}$ was measured by a spectrophotometer (Spectronic 200). A control assay was performed by adding distilled water instead of cricket hydrolysate. DPPH radical scavenging activity was calculated by the following equation: DPPH radical scavenging $\%=\left[\left(A_{0}-A_{1}\right) / A_{0}\right] \times 100$, where $A_{0}$ is the absorbance of the DPPH solution (control) and $A_{1}$ is the absorbance of the sample.

2.9. Ferric Reducing Antioxidant Power (FRAP) Assay. The FRAP assay of freeze-dried cricket hydrolysates was carried out according to the method of Rabeta and Faraniza [12]. The FRAP reagent was obtained by mixing $0.3 \mathrm{M}$ acetate buffer (pH 3.6), $10 \mathrm{mM}$ 2,4,6-Tris(2-pyridyl)-s-triazine (TPTZ) dissolved in $40 \mathrm{mM} \mathrm{HCl}$, and $2 \mathrm{mM} \mathrm{FeCl}_{3}$ in a ratio of $10: 1: 1$. Two hundred microliters of freeze-dried cricket hydrolysates dissolved in deionized water with $1 \mathrm{mg} / \mathrm{mL}$ protein content was mixed with $3 \mathrm{~mL}$ of FRAP reagent then incubated for 30 minutes in a water bath at $37^{\circ} \mathrm{C}$. Afterwards, the absorbances of the sample mixtures were measured at $593 \mathrm{~nm}$ in a spectrophotometer (Spectronic 200). A standard curve was obtained by conducting the assay with different concentrations of $\mathrm{FeSO}_{4} \cdot 7 \mathrm{H}_{2} 0$, and the assay results were expressed as $\mathrm{Fe}^{2+}$ equivalents $(\mathrm{mM})$ per gram of samples.

2.10. Statistical Analyses. Results are expressed as means \pm standard deviations of triplicate analyses for each sample. Differences between samples that underwent different treatments were analyzed by applying Student's $t$-test. Data on protein content was statistically analyzed by One-way Anova followed by Duncan's multiple range test using SPSS Statistics (version 18). The level of significant difference was considered at a $p$ value less than 0.05 .

\section{Results and Discussion}

3.1. Microbiological Analysis of Frozen Bamboo Caterpillar, Field Cricket, and Silkworm. The results of microbial analyses of three Thai commercial frozen edible insect products are shown in Table 1. Total bacterial numbers in the three frozen samples were about 8-8.4 log cfu/g while lactic acid bacteria, yeasts and molds, Enterobacteriaceae, and Clostridium spp. numbers were in the range of $0-5.2,5.6-6.3,4.7-6.6$, and 3.2-3.6 cfu/g, respectively. Total aerobic mesophilic bacterial numbers were found comparable to published data on fresh silkworm [5].

Prior quantitative microbial analyses on field cricket and bamboo caterpillar are lacking; however, comparing our data to published findings on other edible insects (reviewed by Garofalo et al. [13]), it can be concluded that the three frozen insect samples had moderate microbial load in the specific microbe groups that were investigated (total aerobic mesophiles, lactic acid bacteria, yeasts and molds, Enterobacteriaceae, and Clostridium spp.). On the other hand, it is unclear how these commercial frozen insect products are actually made, e.g., how long time has passed between killing and freezing these insects and under what environmental conditions. Nevertheless, after freezing, the insect samples' microbial loads are still can be considered moderate, which indicates that the freezing process cannot be relied on as to drastically reduce the number of microbes associated with the insects. Therefore, proper food processing practices are advisable to ensure the appropriate microbial qualities of the human dietary products made from such frozen insect raw materials.

3.2. Protein Content and Extraction. Total crude protein content determination by the Kjeldahl method (Table 2) revealed that field cricket had the highest proportion of protein (on dry weight basis) among the three frozen insects (about $52 \%)$ which is comparable to chicken meat's protein content (60\% protein/dry weight [14]). However, the crude protein 
TABLE 1: Microbial analysis of frozen insects.

\begin{tabular}{lccccc}
\hline Frozen insects & Total aerobic mesophiles & Lactic acid bacteria & Yeasts and molds & Enterobacteriaceae & Clostridium spp. \\
\hline Bamboo caterpillar & $8.37 \pm 0.05$ & $5.21 \pm 0.2$ & $6.27 \pm 0.23$ & $6.56 \pm 0.17$ & $3.60 \pm 0.2$ \\
Field cricket & $7.94 \pm 0.04$ & ND & $5.59 \pm 0.43$ & $6.18 \pm 0.11$ & $3.19 \pm 0.6$ \\
Silkworm & $8.13 \pm 0.17$ & ND & $5.85 \pm 0.22$ & $4.71 \pm 0.41$ & $3.33 \pm 0.19$ \\
\hline
\end{tabular}

Data $(\log \mathrm{cfu} / \mathrm{g})$ are the mean \pm standard deviations of three replicates. N.D.: not detected.

TABLe 2: Dry matter and protein content in selected insects.

\begin{tabular}{lcc}
\hline Insect samples & Dry matter (\%) & Protein (\% of dry weight) \\
\hline Bamboo caterpillar & $32.69 \pm 0.68$ & $47.52 \pm 0.55 b$ \\
Field cricket & $28.74 \pm 1.04$ & $52.08 \pm 0.13 a$ \\
Silkworm & $23.49 \pm 0.48$ & $48.2 \pm 0.84 b$ \\
\hline
\end{tabular}

Mean values \pm standard deviation $(n=3)$. Values with different letters within a column are significantly different $(p<0.05)$.

contents of bamboo caterpillar and silkworm were not far behind of the field cricket's ( 47.5 and $48.2 \%$, respectively), underlying the potential value of these insects as novel nutritional protein sources.

Obtaining and separating the protein content from the insect body has its advantages and challenges from the food technologist's point of view, one of which is defatting the insects. Defatting procedures remove most of the lipids that form biological membranes therefore allowing easier access to both membrane and cytoplasmic proteins during a subsequent protein isolation/extraction process. In this work, two defatting methods were combined with protein isolation by isoelectric point precipitation at $\mathrm{pH} 3.5$ or 4.5 . The results presented in Table 3 show that in cases of cricket and bamboo caterpillar, the Soxhlet defatting method and the Folch lipid extraction combined with isoelectric point precipitation yielded similar protein content when compared at $\mathrm{pH} 3.5$ or $\mathrm{pH}$ 4.5. More precisely, there was no significant difference in protein yield between the defatting methods and between isoelectric point precipitations at different $\mathrm{pHs}$ in field cricket and bamboo caterpillar samples. This indicates that from certain insect protein could be extracted in similar efficiency regardless of defatting method or isoelectric point precipitation $\mathrm{pH}$, which might be a general rule but there can be exceptions such as in silkworm. As the results indicate, the protein yield in silkworm was higher at pH 3.5 in the Soxhlet defatted sample, as opposed to the Folch method treated sample where higher protein yield was obtained at $\mathrm{pH} 4.5$. The reason behind this observation may lie in the lipid composition of the silkworm as well as its lipids association with more or less negatively charged proteins. For example, Soxhlet extraction with the less polar petroleum ether might expose a higher amount of more negatively charged proteins (isolated at pH 3.5) than the more polar solvents (dichloromethane and methanol) in Folch extraction. Similarly, the same polar solvents in Folch extraction might liberate a higher amount of less negatively charged proteins (precipitated at $\mathrm{pH}$ 4.5) than did petroleum ether in the Soxhlet method.
3.3. Subcritical Water Hydrolysis of Defatted Crickets. Isolated insect proteins, apart from being a novel option for human nutrition, may have other interesting features. To explore additional nutritional benefits of insect proteins, field crickets were subjected to another set of experiments based on the fact that they were found to have the highest relative protein content among the three examined frozen insect samples. To investigate other potential nutritional benefits, defatted field crickets were subjected to subcritical water hydrolysis $\left(121\right.$ or $135^{\circ} \mathrm{C}$ for 15 or 30 minutes). The effect of these hydrothermal treatments on the total crude protein content is shown in Table 4. These results show that the total crude protein contents after hydrothermal treatments were lower than that of the untreated control (homogenized defatted cricket). This result can be attributed to the hydrothermal treatments which must have been produced a certain amount of cricket protein-derived oligopeptides and free amino acids [15], the latter being unreactive in the Lowry assay; hence, the decreased amount of peptide bonds resulted in less detected protein amounts.

3.4. Antioxidant Activities of Subcritical Water Hydrolysates of Field Cricket. DPPH radical scavenging activity assay and ferric reducing antioxidant power (FRAP) assay were carried out to test the potential antioxidant properties of hydrothermal cricket hydrolysates. The results of DPPH scavenging activities of defatted cricket hydrolysates shown in Table 4 indicated higher DPPH scavenging abilities of the hydrolysates than that of the control (untreated) defatted field cricket sample. The highest DPPH scavenging activity was detected in the hydrolysate treated at $135^{\circ} \mathrm{C}$ for 15 minutes followed by products of treatments at $121^{\circ} \mathrm{C}$ for 30 minutes, $121^{\circ} \mathrm{C}$ for 15 minutes, and $135^{\circ} \mathrm{C}$ for 30 minutes, respectively. The DPPH scavenging activity seemed to increase with higher temperature/longer time treatments except for $135^{\circ} \mathrm{C}$ 30 minutes treatment which resulted in the smallest activity among the treatments, although still higher than that of the control. Given the finding that defatted crickets contain relatively high amount of proteins, it seems likely that the effects of the applied hydrothermal treatments on the crickets' protein content at least partly responsible for the DPPH scavenging activity increase in the treated samples. It is known from other works [15-17] that even mild hydrothermal treatments can cause partial hydrolysis of proteins which results in the liberation of free amino acids and oligopeptides. It is also known that some free amino acids such as histidine [18] and tryptophan [19] as well as certain oligopeptides derived from hydrolysis of proteins exhibit free radical scavenging activity [20-22]. Therefore, taken the above observations 
TABle 3: Protein content ( $\mathrm{mg} / \mathrm{mg}$ defatted insect) of defatted insects after lipid removal at different pHs followed by isoelectric point precipitation.

\begin{tabular}{lcccc}
\hline Lipid removal & \multicolumn{2}{c}{ Soxhlet method } & \multicolumn{2}{c}{ Folch method } \\
Isoelectric point precipitation & $\mathrm{pH} 3.5$ & $\mathrm{pH} 4.5$ & $\mathrm{pH} 3.5$ & $0.18 \pm 0.008$ \\
\hline Bamboo caterpillar & $0.153 \pm 0.01$ & $0.172 \pm 0.002$ & $0.167 \pm 0.007$ & $0.695 \pm 0.004$ \\
Field cricket & $0.676 \pm 0.012$ & $0.681 \pm 0.024$ & $0.734 \pm 0.019$ & $0.435 \pm 0.019^{*}$ \\
Silkworm & $0.462 \pm 0.005^{*}$ & $0.323 \pm 0.017^{*}$ & $0.265 \pm 0.008^{*}$ & $\mathrm{p}^{*}$ \\
\hline
\end{tabular}

Mean values \pm standard deviation $(n=3)$. ${ }^{*}$ Significantly different $(p \leq 0.05)$ from that isoelectric point precipitation conducted at different $\mathrm{pH}$ after the same lipid removal method.

TABLE 4: Protein content, DPPH radical scavenging activity, and FRAP of defatted field cricket before and after subcritical water hydrolyses.

\begin{tabular}{lccc}
\hline $\begin{array}{l}\text { Hydrothermal } \\
\text { treatment of } \\
\text { defatted field } \\
\text { cricket }\end{array}$ & $\begin{array}{c}\text { Protein (g/g of } \\
\text { freeze-dried } \\
\text { sample) }\end{array}$ & $\begin{array}{c}\text { DPPH radical } \\
\text { scavenging } \\
\text { activity }(\%)\end{array}$ & $\begin{array}{c}\mathrm{FRAP}(\mathrm{mM} \\
\mathrm{Fe}^{2+} \text { eq./g) }\end{array}$ \\
\hline $\begin{array}{l}\text { Control } \\
\text { (untreated) }\end{array}$ & $1.23 \pm 0.13$ & $0.07 \pm 0.08$ & $0.30 \pm 0.10$ \\
$121^{\circ} \mathrm{C}, 15 \mathrm{~min}$ & $0.86 \pm 0.1^{*}$ & $39.45 \pm 1.72^{*}$ & $0.97 \pm 0.06^{*}$ \\
$121^{\circ} \mathrm{C}, 30 \mathrm{~min}$ & $0.66 \pm 0.08^{* \#}$ & $44.68 \pm 0.88^{* \S}$ & $1.01 \pm 0.03^{*}$ \\
$135^{\circ} \mathrm{C}, 15 \mathrm{~min}$ & $0.63 \pm 0.11^{* \#}$ & $45.51 \pm 2.64^{* \S}$ & $0.79 \pm 0.07^{*}$ \\
$135^{\circ} \mathrm{C}, 30 \mathrm{~min}$ & $0.61 \pm 0.16^{* \#}$ & $28.41 \pm 8.11^{*}$ & $1.13 \pm 0.04^{*}$ \\
\hline
\end{tabular}

Mean values \pm standard deviation $(n=3)$. ${ }^{*}$ Significantly different $(p \leq 0.05)$ from that of the Control. " Significantly different $(p \leq 0.05)$ from that of the sample treated at $121^{\circ} \mathrm{C}$ for 15 minutes. ${ }^{\circledR}$ Significantly different $(p \leq 0.05)$ from that of the sample treated at $121^{\circ} \mathrm{C}$ for 15 minutes and at $135^{\circ} \mathrm{C}$ for $30 \mathrm{~min}$.

together, we postulate that the applied hydrothermal treatments on defatted crickets released free amino acids and oligopeptides which contributed substantially to the DPPH scavenging activity of the samples that underwent hydrothermal treatment. However, it is also documented that the total polyphenol index in the water soluble extract of defatted crickets (Acheta domesticus) is relatively high among edible insects [2]. This finding implies that polyphenolic compounds may also contributed to the DPPH scavenging activities detected in those defatted crickets which are relatives of the field crickets (Gryllus bimaculatus). Additionally, it may also be possible that the applied hydrothermal treatments have positively influenced the bioavailability of polyphenolic compounds in our field cricket samples (similarly to that in defatted grape seeds [23] or in defatted orange peels [24]), which in turn were also involved in the observed increase of antioxidant activities of said cricket samples. In the light of the above observations, it can be speculated that on one hand increased hydrothermal treatment temperature and time duration increased antioxidant peptides and amino acid content in the treated samples as well as increased free polyphenol content as well. However, the observed low DPPH scavenging activity in the sample after the highest temperature-longest time hydrothermal treatment does not fit this pattern for uncertain reasons, for example something might interfere with the released antioxidant compounds. One possibility is that more intense subcritical water extraction might liberate other compounds as well (e.g., mono or oligosaccharides from chitin) that might enter chemical reactions with antioxidant compounds (e.g., Maillard reactions with amino acids) thus reducing the overall DPPH scavenging ability of the sample.

The results of the ferric reducing antioxidant power assay shown in Table 4 have similarities to DPPH radical scavenging activity results such as all the treated samples exhibited higher FRAP values than that of the untreated control. At both treatment temperatures, FRAP values were lower in the samples that underwent shorter treatment time (15 minutes), than in samples treated for a longer time (30 minutes). However, both samples treated at $121^{\circ} \mathrm{C}$ had higher FRAP values than that of treated at $135^{\circ} \mathrm{C}$ for $15 \mathrm{~min}$, while the highest FRAP value was measured in the sample treated at $135^{\circ} \mathrm{C}$ for 30 minutes. Similar to that of DPPH radical scavenging activity discussed above, higher FRAP values in samples after hydrothermal treatments might be due to the cumulative effect of different compounds such as amino acids, oligopeptides, and polyphenols liberated from the defatted field cricket tissues by the treatments. It is likely that the hydrolytic effect of the hydrothermal treatments freed up amino acids such as cysteine and tryptophan with high FRAP values [25] as well as oligopeptides and polyphenolic compounds at various degrees and efficiencies, and these could effectively donate electrons or hydrogen to reduce the $\mathrm{Fe}^{3+}$. TPTZ complex. Our results also complement the finding of Di Mattia et al. [2] who reported relatively high FRAP value of defatted crickets (Acheta domesticus) among the tested edible insects.

\section{Conclusions}

This study focused on the microbial quality, defatting and protein extraction yield, and antioxidant properties of three edible insects whose general perception as dietary raw materials in western societies are mainly repulsive despite their relatively high protein content. It was found that a Thai commercial frozen product of either silkworm (Bombyx mori), bamboo caterpillar (Omphisa fuscidentalis), or field cricket (Gryllus bimaculatus) contained moderate microbial loads which potentially be further reduced by food preparation practices. Protein yields from the above insects after isoelectric point precipitation were compared and related to the defatting methods used. This revealed that the defatting 
method influenced the protein yield from only one of the three insects. Additionally, free radical scavenging and ferric reducing antioxidant power measurements were performed on subcritical water hydrolysates of defatted field crickets. The results of these measurements showed that the applied hydrothermal treatments were able to liberate compounds with antioxidant activities from the defatted insect samples.

\section{Data Availability}

The data used and/or analyzed in the study are available from the corresponding author on reasonable request.

\section{Conflicts of Interest}

The authors declare that there is no conflict of interest regarding the publication of this article.

\section{Acknowledgments}

This research was funded as a part of employment and as senior project support by Mahidol University International College, Thailand.

\section{References}

[1] A. van Huis, J. van Itterbeek, H. Klunder et al., "Edible insects. Future prospects for food and feed security," FAO Forestry Paper, vol. 171, pp. 59-88, 2013.

[2] C. Di Mattia, N. Battista, G. Sacchetti, and M. Serafini, “Antioxidant activities in vitro of water and liposoluble extracts obtained by different species of edible insects and invertebrates," Frontiers in Nutrition, vol. 6, p. 106, 2019.

[3] C. Botella-Martínez, R. Lucas-González, J. A. Pérez-Álvarez, J. Fernández-López, and M. Viuda-Martos, "Assessment of chemical composition and antioxidant properties of defatted flours obtained from several edible insects," Food Science and Technology International, vol. 39, 2020.

[4] E. Zielińska, B. Baraniak, and M. Karaś, "Antioxidant and antiinflammatory activities of hydrolysates and peptide fractions obtained by enzymatic hydrolysis of selected heat-treated edible insects," Nutrients, vol. 9, no. 9, p. 970, 2017.

[5] L. Fasolato, B. Cardazzo, L. Carraro, F. Fontana, E. Novelli, and S. Balzan, "Edible processed insects from e-commerce: food safety with a focus on the Bacillus cereus group," Food Microbiology, vol. 76, pp. 296-303, 2018.

[6] W. Horwitz and G. W. Latimer, Eds., Official Methods of Analysis of AOAC International, AOAC International, Gaithersburg, MD, USA, 18th edition, 2005.

[7] R. H. Janssen, J.-P. Vincken, L. A. M. van den Broek, V. Fogliano, and C. M. M. Lakemond, "Nitrogen-to-protein conversion factors for three edible insects: Tenebrio molitor, Alphitobius diaperinus, and Hermetia illucens," Journal of Agricultural and Food Chemistry, vol. 65, no. 11, pp. 22752278, 2017.

[8] D. A. Tzompa-Sosa, L. Yi, H. J. F. van Valenberg, M. A. J. S. van Boekel, and C. M. M. Lakemond, "Insect lipid profile: aqueous versus organic solvent-based extraction methods," Food Research International, vol. 62, pp. 1087-1094, 2014.

[9] F. Gresiana, A. M. Ir Marpaung, and H. Sutanto, "Protein isolation from cricket (Gryllus mitratus)," in Proceedings of the
International Conference on Innovation, Entrepreneurship and Technology, pp. 214-221, Swiss German University, Indonesia, 2015.

[10] J. H. Waterborg, "The Lowry method for protein quantitation," in The Protein Protocols Handbook, J. M. Walker, Ed., pp. 7-10, Humana Press Inc., Totowa, NJ, USA, 2nd edition, 2002.

[11] A. Bougatef, N. Nedjar-Arroume, L. Manni et al., "Purification and identification of novel antioxidant peptides from enzymatic hydrolysates of sardinelle (Sardinella aurita) byproducts proteins," Food Chemistry, vol. 118, no. 3, pp. 559$565,2010$.

[12] M. S. Rabeta and F. R. Nur, "Total phenolic content and ferric reducing antioxidant power of the leaves and fruits of Garcinia atroviridis and Cynometra cauliflora," International Food Research Journal, vol. 20, pp. 1691-1696, 2013.

[13] C. Garofalo, V. Milanović, F. Cardinali, L. Aquilanti, F. Clementi, and A. Osimani, "Current knowledge on the microbiota of edible insects intended for human consumption: a state-of-the-art review," Food Research International, vol. 125, article 108527, 2019.

[14] L. F. de Souza, D. N. Araújo, L. M. Stefani et al., "Probiotics on performance, intestinal morphology and carcass characteristics of broiler chickens raised with lower or higher environmental challenge," Australian Journal of Veterinary Sciences, vol. 50, no. 1, pp. 35-41, 2018.

[15] W. Lamoolphak, W. De-Eknamkul, and A. Shotipruk, "Hydrothermal production and characterization of protein and amino acids from silk waste," Bioresource Technology, vol. 99, no. 16, pp. 7678-7685, 2008.

[16] W. Lamoolphak, M. Goto, M. Sasaki, M. Suphantharika, C. Muangnapoh, and A. Shotipruk, "Hydrothermal decomposition of yeast cells for production of proteins and amino acids," Journal of Hazardous Materials B, vol. 137, no. 3, pp. 1643-1648, 2006.

[17] K. Y. Kang and B. S. Chun, "Behavior of hydrothermal decomposition of silk fibroin to amino acids in near-critical water," Korean Journal of Chemical Engineering, vol. 21, no. 3, pp. 654-659, 2004.

[18] A. M. Wade and H. N. Tucker, "Antioxidant characteristics of L-histidine," Journal of Nutritional Biochemistry, vol. 9, no. 6, pp. 308-315, 1998.

[19] B. N. Nayak and H. S. Buttar, "Evaluation of the antioxidant properties of tryptophan and its metabolites in in vitro assay," Journal of Complementary and Integrative Medicine, vol. 13, no. 2, pp. 129-136, 2016.

[20] H.-C. Wu, H.-M. Chen, and C.-Y. Shiau, "Free amino acids and peptides as related to antioxidant properties in protein hydrolysates of mackerel (Scomber austriasicus)," Food Research International, vol. 36, no. 9-10, pp. 949-957, 2003.

[21] H.-C. Wu, C.-Y. Shiau, H.-M. Chen, and T.-K. Chiou, "Antioxidant activities of carnosine, anserine, some free amino acids and their combination," Journal of Food and Drug Analysis, vol. 11, no. 2, p. 13, 2003.

[22] H. Guo, Y. Kouzuma, and M. Yonekura, "Structures and properties of antioxidative peptides derived from royal jelly protein," Food Chemistry, vol. 113, no. 1, pp. 238-245, 2009.

[23] K. S. Duba, A. A. Casazza, H. B. Mohamed, P. Perego, and L. Fiori, "Extraction of polyphenols from grape skins and defatted grape seeds using subcritical water: experiments and modeling," Food and Bioproducts Processing, vol. 94, pp. 29$38,2015$. 
[24] D. Lachos-Perez, A. M. Baseggio, P. C. Mayanga-Torres et al., "Subcritical water extraction of flavanones from defatted orange peel," Journal of Supercritical Fluids, vol. 138, pp. 716,2018

[25] A. Guidea, C. Zăgrean-Tuza, A. C. Moț, and C. Sârbu, "Comprehensive evaluation of radical scavenging, reducing power and chelating capacity of free proteinogenic amino acids using spectroscopic assays and multivariate exploratory techniques," Spectrochimica Acta Part A: Molecular and Biomolecular Spectroscopy, vol. 233, article 118158, 2020. 